\title{
ESTUDO E APLICAÇÃO DAS FERRAMENTAS DE CONTROLE DA QUALIDADE EM UMA INDÚSTRIA DE PROCESSAMENTO DE SEMENTES OLEAGINOSAS.
}

Larissa Brito Santos de Aguiar, Letícia Batoqui Munhoz, Letícia Cristina Rizzo, Lillian Faria Gnann, Andréia de Menezes Olivo.

Universidade do Oeste Paulista - UNOESTE, Faculdade de Engenharia Conselheiro Algacyr Munhoz Maéder, Curso de Engenharia de Produção, Presidente Prudente - SP. E-mail: leticiabatoqui@hotmail.com.

\section{RESUMO}

Diante do cenário industrial atual com forte crescimento econômico, globalização, e os avanços tecnológicos, os consumidores passaram a ser cada vez mais exigentes e criteriosos. Um dos fatores mais importantes para alcançar um diferencial competitivo é a qualidade. O presente artigo tem por objetivo realizar uma análise e aplicação das ferramentas da qualidade em relação aos parâmetros físico químicos do farelo de soja moído de uma indústria processadora de sementes. Verificou-se que a qualidade do produto em estudo está relacionada à conformidade com os valores das especificações do farelo de soja, quanto à umidade, proteína e óleo. A metodologia adotada foi de caráter exploratório, descritivo e analítico, além de uma abordagem quantitativa-qualitativa ao mensurar os problemas e interpretar os resultados obtidos por meio de modelos estatísticos. Os resultados são apresentados através de gráficos, onde concluiu-se que a umidade do farelo analisado é o fator crítico que merece atenção dos gestores.

Palavras-chave: diferencial; ferramentas da qualidade; farelo de soja; parâmetros; especificação.

\section{STUDY AND APPLICATION OF QUALITY CONTROL TOOLS IN AN OLEAGINOUS SEED PROCESSING INDUSTRY.}

\begin{abstract}
Faced with the current industrial scenario with strong economic growth, globalization, and technological advances, consumers have become increasingly demanding and discerning. One of the most important factors to achieve a competitive differential is quality. The present article aims to perform an analysis and application of the quality tools in relation to the physical chemical parameters of the ground soybean meal of a seed processing industry. It was verified that the quality of the product under study is related to the compliance with the values of soybean meal specifications for moisture, protein and oil. The methodology adopted was exploratory, descriptive and analytical, as well as a quantitative-qualitative approach when measuring the problems and interpreting the results obtained through statistical models. The results are presented through graphs, where it was concluded that the moisture of the analyzed bran is the critical factor that deserves attention of the managers.
\end{abstract}

Keywords: differential; quality tools; soybean meal; parameters; specification. 


\section{INTRODUÇÃO}

Com a alta competitividade do mercado as empresas têm buscado cada vez mais atingir uma vantagem em relação a seus concorrentes, um dos fatores mais importantes para garantir tal diferencial é a qualidade de produtos e serviços, que passou a ser obrigação no cenário atual. Para Lobo (2010) a qualidade se tornou um fator de mercado, onde os clientes exigem segurança, produtos excelentes e de qualidade técnica elevada, ainda com preços acessíveis.

As ferramentas de controle da qualidade são utilizadas para desenvolver métodos de identificação e eliminação de falhas que contribuem para a otimização das operações e melhoria da qualidade. Segundo Carvalho e Paladini (2012) essas ferramentas são de simples utilização, aplicadas para selecionar, implantar ou avaliar modificações no processo produtivo com o objetivo de gerar melhorias. As sete ferramentas básicas da qualidade são: estratificação, folha de verificação, gráfico de Pareto, diagrama Ishikawa, histograma, diagrama de dispersão, gráfico de controle; e além dessas, o Brainstorming e o 5W2H são outras ferramentas bastante difundidas.

A empresa abordada no presente estudo é uma agroindústria que tem suas atividades voltadas para a extração de óleo bruto de soja e produção de farelo de soja moído e peletizado. $\mathrm{Na}$ agroindústria, a soja tem grande relevância devido à importância de seus produtos destinados ao consumo humano e animal. O farelo de soja é utilizado como ingrediente na formulação de rações animais oferecendo maior desempenho nutricional devido ao alto valor proteico e baixo teor de óleo.

No processo de produção do farelo de soja, a matéria prima passa primeiramente pela peneira de pré-limpeza para retirada dos resíduos grossos e finos. Em sequência, a secagem reduz a umidade dos grãos que são recebidos. Nos quebradores, a soja é quebrada através da passagem entre rolos e as cascas que se soltam são retiradas através de cortinas de ar.

A etapa posterior à quebra é o condicionamento através de breve cozimento da massa e a laminação, que consiste na passagem do produto condicionado entre rolos, formando uma lâmina. A lâmina é transportada até o expander, onde é submetida a pressão e calor, propiciando a expansão das moléculas de óleo e formando uma massa expandida preparada para extração onde será lavada com solvente. O farelo branco é transportado até o DT onde irá passar pelo processo de dessolventização e tostagem, dando origem ao farelo final. O farelo será secado e tostado através da injeção de ar quente, e resfriado através da injeção de ar frio. O farelo é compactado em uma peletizadora depois seguirá para a estocagem no armazém (farelo de soja peletizado), ou seguirá para o armazém de farelo Mercado Interno.

$\mathrm{Na}$ produção do farelo de soja, é fundamental que sejam realizadas análises e monitoramentos constantes para avaliar suas características e especificações nutricionais necessárias para o animal, assim garantindo a qualidade do produto. Com isso, o presente trabalho tem o objetivo de analisar os teores dos principais componentes nutricionais que compõem o farelo de soja: a proteína, o óleo e a umidade.

\section{METODOLOGIA}

A metodologia utilizada foi de caráter exploratório, descritivo e analítico em uma empresa de processamento de sementes oleaginosas, onde foram aplicadas as ferramentas de controle de qualidade visando conduzir a uma análise como possibilidade para a identificação de falhas que influenciam na qualidade do produto final.

Segundo Rodrigues (2015, p. 91) “o objetivo da pesquisa exploratória é explorar ou examinar um problema para proporcionar conhecimento e compreensão mais abrangente sobre ele", ou seja, familiarizar-se com o que será investigado obtendo informações em relação aos problemas que a empresa esteja enfrentando.

O processo descritivo tem como objetivo a identificação, registro e análise dos fatores ou variáveis que se relacionam com o processo. Esse tipo de pesquisa pode ser entendida como um 
estudo de caso onde, após a coleta de dados, é realizada uma análise das relações entre as variáveis para uma posterior determinação dos efeitos resultantes em uma empresa, sistema de produção ou produto. Já as pesquisas analíticas envolvem o estudo e avaliação aprofundados de informações disponíveis na tentativa de explicar o contexto de um fenômeno. (BARROS; LEHFELD,2007)

A utilização das ferramentas de qualidade visam contribuir na investigação dos pontos críticos do processo, por intermédio da aplicação de conceitos, coleta de dados e do diagnóstico das possíveis não conformidades em todas as etapas, com intuito de auxiliar e apoiar a gerência na tomada de decisões para a resolução dos problemas.

No presente estudo foram analisados os valores das especificações do farelo de soja moído produzidos pela empresa analisada, quanto à umidade, proteína e óleo, que seguem a portaria no 795, de 15 de dezembro de 1993 do Ministério da Agricultura, Pecuária e Abastecimento (MAPA): teor de umidade com máximo de $12,5 \%$, proteína com mínimo de $46 \%$ e óleo com máximo de $2,5 \%$.

\section{RESULTADOS}

Com o objetivo de analisar os parâmetros da proteína, do óleo e da umidade, principais componentes nutricionais presentes no farelo de soja, foram analisados os dados de análises colhidos pela empresa durante a produção de farelo de soja do ano de 2016.

A aplicação do Diagrama de Pareto possibilitou a identificação do parâmetro que merece maior atenção para que sejam tomadas medidas necessárias na eliminação das causas de sua ocorrência:

GRÁFICO 1. Frequência de ocorrência em relação aos parâmetros físico químicos do farelo de soja

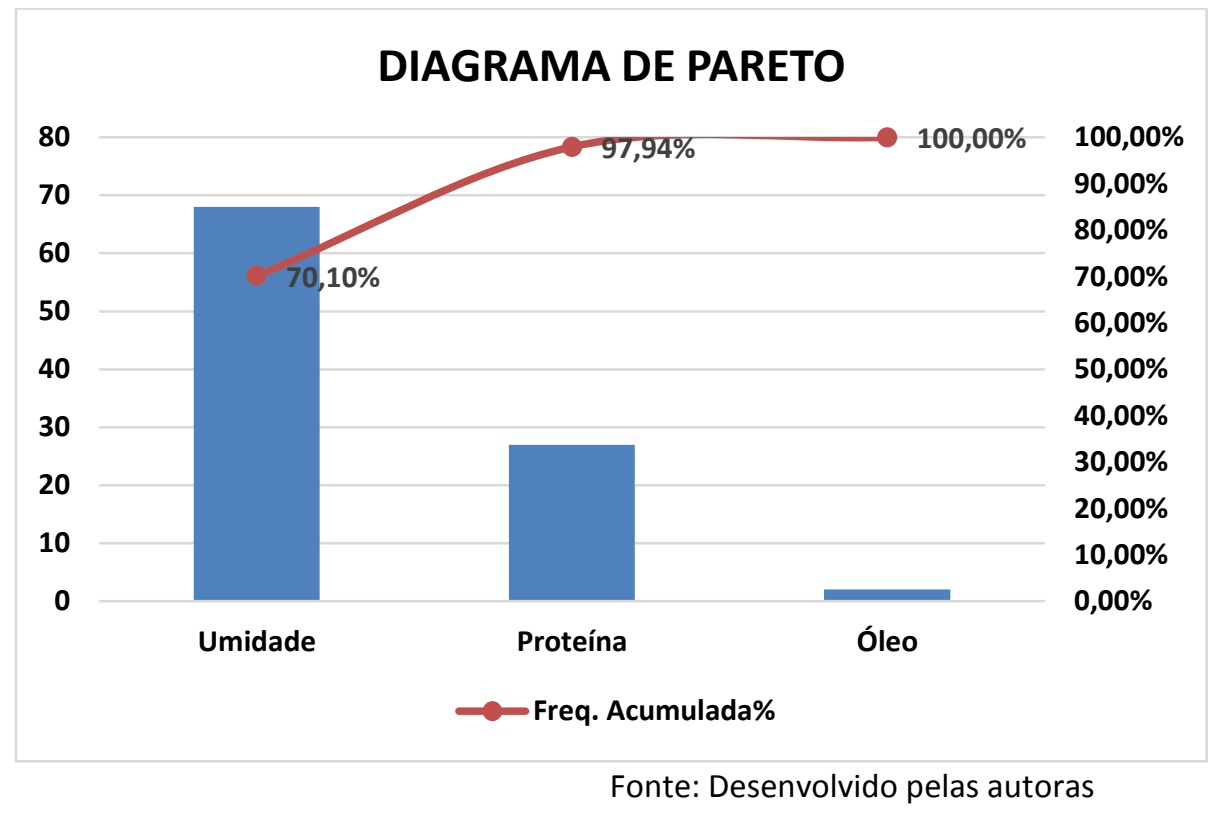

O Digrama de Ishikawa foi elaborado baseado no parâmetro umidade, pois é o fator que apresenta maior ocorrência de frequência $(70,10 \%)$ em relação aos demais parâmetros utilizados para análise: 
FIGURA 1. Diagrama de causas e efeitos do processo

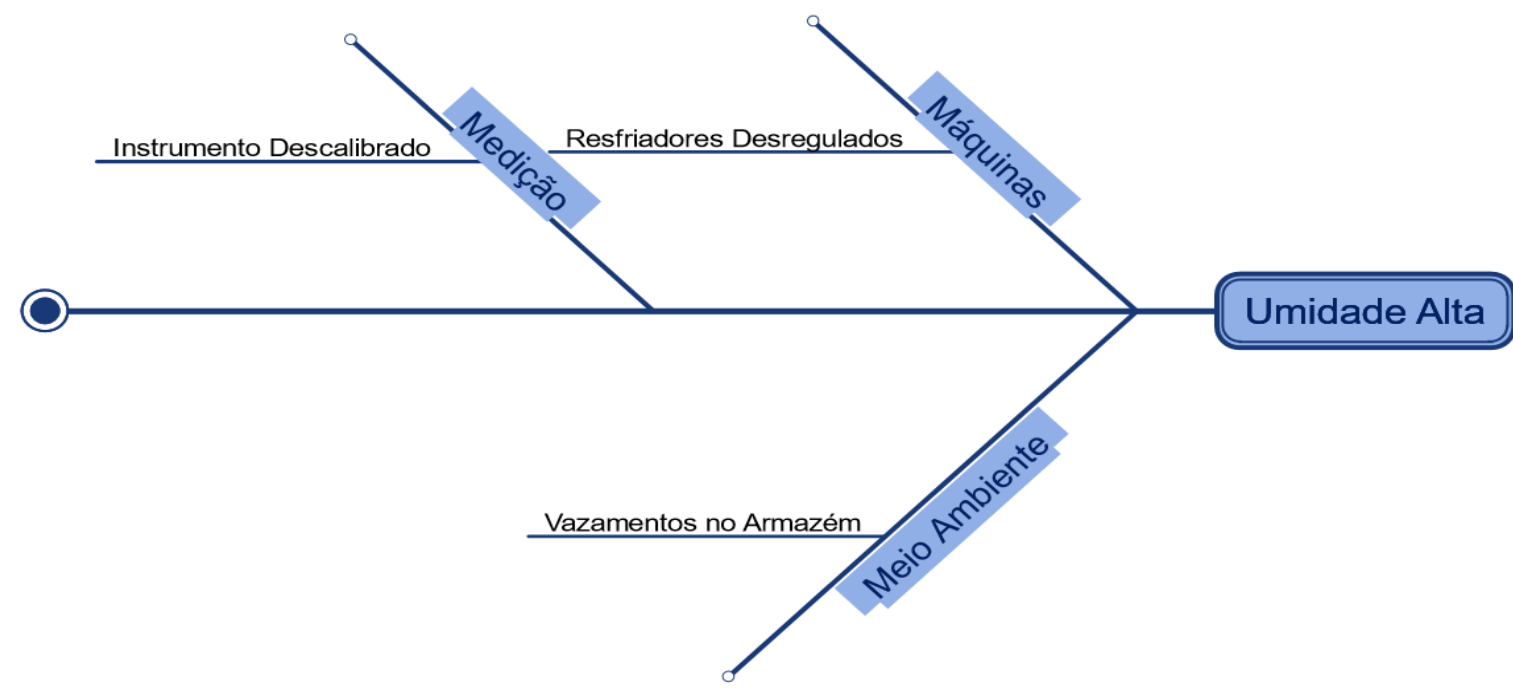

Fonte: Desenvolvido pelas autoras

O Diagrama de Dispersão possibilitou a representação gráfica de valores de dois parâmetros relacionados ao farelo de soja, sendo utilizado para mostrar o que acontece com um parâmetro quando o outro se altera, ajudando a visualizar a relação ou não entre eles. $A$ análise foi realizada com os índices de umidade e de proteína do farelo de soja:

GRÁFICO 2. Correlação entre Umidade e Proteína

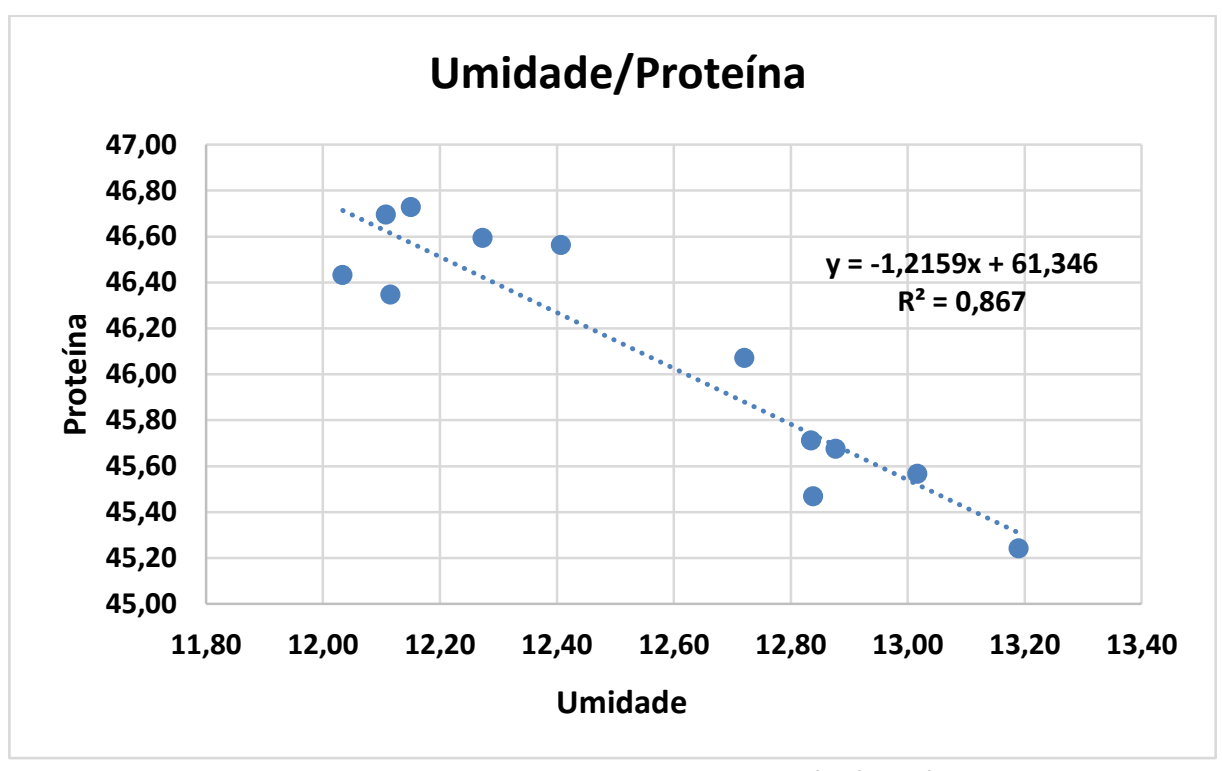

Fonte: Desenvolvido pelas autoras

A Carta Controle foi aplicada com o objetivo de verificar se o processo de produção do farelo de soja está sob controle de acordo com o limite inferior e superior determinados pela ferramenta, mostrando se há variações e onde se deve utilizar medidas corretivas apropriadas. Para análise dessa ferramenta foram utilizados dados de amostragem do período de 02/05/2016 à 07/05/2016, totalizando seis dias: 
GRÁFICO 3. Carta controle da média da umidade do farelo de soja

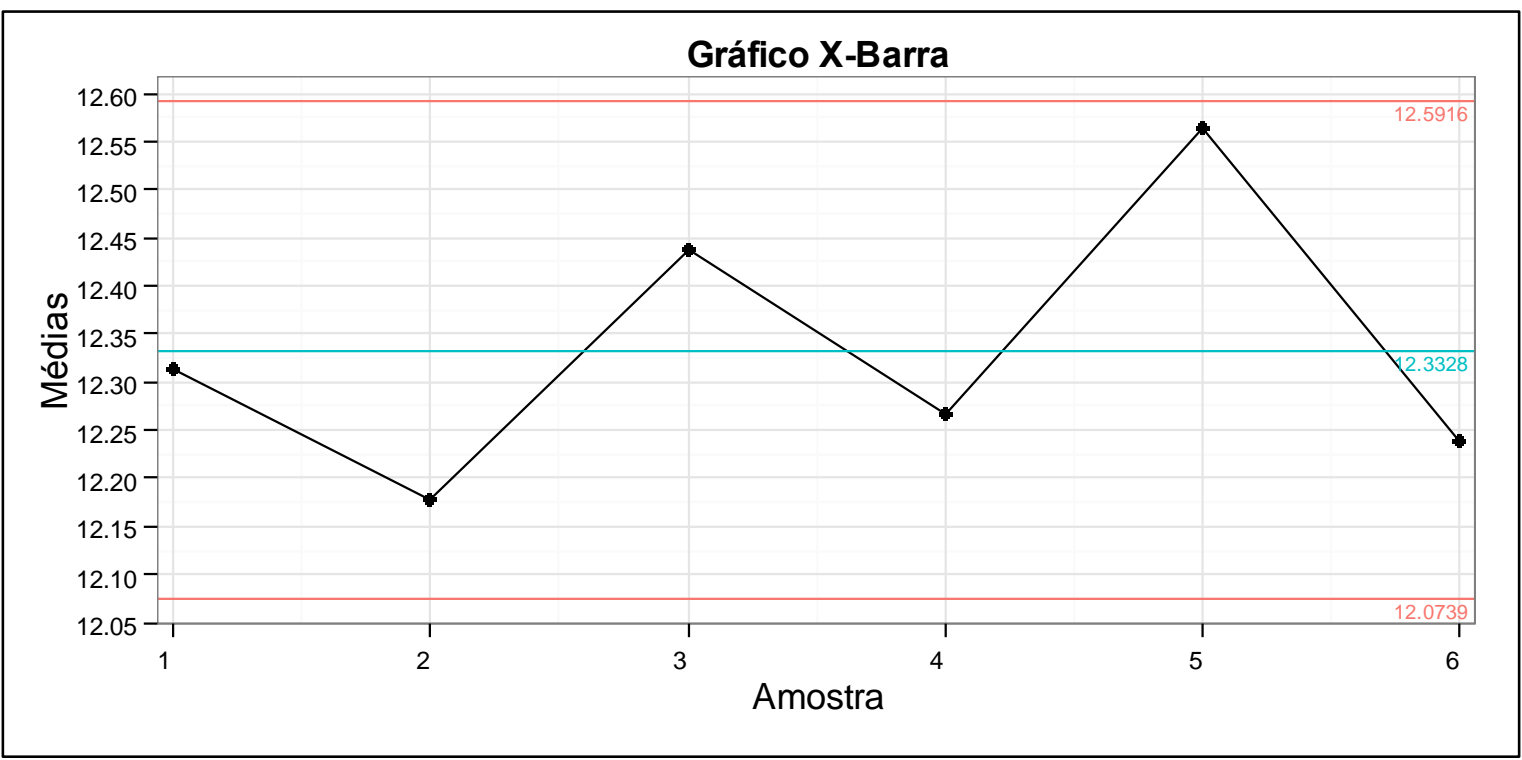

Fonte: Desenvolvido pelas autoras

\section{DISCUSSÃO}

As ferramentas para controle da qualidade são utilizadas com o intuito de propor soluções para problemas que eventualmente interferem no desempenho de processos. Para o desenvolvimento do presente artigo foi necessário o conhecimento tanto do conteúdo teórico quanto prático de cada uma das ferramentas para que fosse possível aplicá-las em uma indústria de processamento de soja.

A primeira ferramenta utilizada foi o Diagrama de Pareto que possibilitou a visualização gráfica dos dados obtidos pela empresa, o que facilitou na identificação do parâmetro mais frequente de falhas durante o processo para obtenção do farelo de soja. A umidade foi a mais representativa totalizando $70,10 \%$ de frequência no período analisado, indicando assim prioridade em relação aos outros.

Para a elaboração do Diagrama de Ishikawa, foi necessário inicialmente o desenvolvimento de um Brainstorming, que é um método com o objetivo de gerar novas ideias de maneira coletiva a partir de um grupo, partindo da ideia de que um grupo gera mais ideias do que um indivíduo isoladamente (LOBO, 2010).

Para o brainstorming foi feito um debate entre as desenvolvedoras do artigo com informações passadas pela empresa e o conhecimento do processo, para levantamento das prováveis causas que contribuem para que a umidade do farelo durante o processo tenha um elevado índice de frequência acima do ideal. Durante o debate cinco situações foram apontadas como as principais causas, são elas: resfriadores desregulados, coleta de amostras inadequada, vapores desregulados, instrumento de medição descalibrado e massa expandida com alta umidade.

Para o desenvolvido do Diagrama de Ishikawa foi realizado um estudo detalhado das causas relacionadas no brainstorming, o que resultou em três situações apenas: possível armazenamento do produto final inadequado, instrumento de medição da umidade descalibrado e resfriadores desregulados. Essas causas foram relacionadas no diagrama com base nos fatores dos $6 \mathrm{Ms}$ (mão de obra, materiais, máquinas, métodos, meio ambiente e medição).

Com o conhecimento das causas primárias, a etapa seguinte foi a elaboração de um Plano de Ação a fim de relacionar as providências a serem tomadas para as causas principais apontadas no diagrama de Ishikawa. 
O Plano de Ação adotado foi o 5W2H que consiste em responder a sete questionamentos a fim de se obter respostas quanto as ações que serão tomadas para a solução de cada problema, são elas: O que? (What), Por que? (Why), Quem? (Who), Onde? (Where), Quando? (When), Como? (How) e Quanto? (How Much). No entanto para o presente estudo foram considerados apenas os questionamentos dos $5 W^{\prime}$ 's e apenas $1 \mathrm{H}$, já que não seria possível ter conhecimento dos valores de investimento nas ações.

No fator Máquina relaciona-se como causa os resfriadores desregulados, na montagem do plano de ação foram respondidos os questionamentos: O que deve ser feito? -Correta regulagem dos resfriadores. Por que? -Para controlar a umidade. Como será feito? -Reduzindo a rotação da esteira do resfriador que transporta o farelo. Quem deve fazer? -O operador de peletização autorizado pelo encarregado de produção. Onde? -No setor de peletização. Quando? -Após resultados de análises e ordem do encarregado de produção.

No fator Medição encontra-se como causa o instrumento de determinação de umidade descalibrado, na montagem do plano de ação foram respondidos os questionamentos: $O$ que deve ser feito? -Calibrar o equipamento. Por que? -Para garantir a veracidade dos resultados apresentados. Como será feito? -Utilizando uma amostra teste para verificação. Quem deve fazer? -O coordenador de controle de qualidade. Onde? -No laboratório. Quando? -Semanalmente.

No fator Meio Ambiente encontra-se como provável causa o armazém do produto final com vazamento. Na montagem do plano de ação foram respondidos os questionamentos: $\mathrm{O}$ que deve ser feito? -Realizar a troca do telhado. Por que? -Para não molhar o farelo moído armazenado. Como será feito? -Utilizando equipamentos e funcionários da empresa. Quem deve fazer? -O coordenador de manutenção. Onde? -No armazém de produto acabado. Quando? -O mais rápido possível quando detectado.

Com a elaboração do diagrama de dispersão foi possível identificar que existe uma correlação negativa entre os parâmetros umidade e proteína, assim quando os valores da umidade atendem à especificação máxima de $12,5 \%$, os índices de proteína também ficam dentro da especificação de no mínimo 46\%. E ao contrário, quando a umidade está alta, a proteína é prejudicada e cai nos seus valores. A relação entre as duas variáveis é de $86,7 \%$ valor este que prova a correlação. Portanto é necessário controlar a umidade para não prejudicar o resultado de proteína do farelo de soja.

$\mathrm{Na}$ carta de controle, o gráfico é representado com eixos que representam as faixas de aceitação, trabalho ou operação, e as análises são realizadas por meio dessas faixas. (SELEME; STANDLER, 2010). Pontos encontrados fora dos limites indicam que o processo está fora do especificado. $\mathrm{O}$ gráfico de controle de média gerado a partir dos dados coletados durante seis dias do mês de maio de 2016, não indicou pontos fora dos limites, então não existem evidências de que o processo esteja fora do controle no período que foi analisado.

\section{CONCLUSÃO}

Os procedimentos aqui descritos demonstram a importância de se melhorar continuamente os processos e produtos de uma organização de uma forma global, para que os produtos tenham alta qualidade e possam ser competitivos no mercado.

A aplicação das ferramentas da qualidade proporcionou o atendimento do objetivo inicial de verificar os teores dos principais componentes nutricionais que constituem o farelo de soja, sendo importantes indicativos de boa ou má qualidade do produto. $\mathrm{O}$ alcance deste objetivo pode atribuir à elevação dos níveis de qualidade por meio da solução eficaz das falhas, diminuindo custos com produtos e processos.

O estudo desenvolvido neste artigo permite concluir que o conceito de qualidade propõe constante busca por melhoria, de modo a satisfazer as necessidades explicitas ou implícitas do consumidor. Com o auxílio das ferramentas da qualidade por meio de métodos estatísticos 
identificou-se que o parâmetro umidade presente no farelo de soja analisado responde por grandes ocorrências de valores acima do especificado.

Tendo em vista a importância do controle de umidade no processo de produção e na composição do produto final, medidas foram sugeridas por meio do Plano de Ação $5 \mathrm{~W} 2 \mathrm{H}$ em busca de correções e adequação do parâmetro que se encontrou fora dos valores especificados.

Foram apontados como prováveis causas para a não conformidade dos valores da umidade do farelo de soja moído analisado a manutenção nos resfriadores que podem estar desregulados durante o processo de produção, o instrumento de determinação de umidade, que deve ser calibrado pois é utilizado de hora em hora e o armazém do produto final no qual foi indicado uma manutenção para controlar os vazamentos existentes.

\section{REFERÊNCIAS}

BARROS, A. J. S.; LEHFELD, N. A. S. Fundamentos de metodologia científica. 3ed. São Paulo: Pearson Prentice Hall, $2007 . \quad$ Disponível em: < http://unoeste.bv3.digitalpages.com.br/users/publications/9788576051565/pages/_1>. Acesso em: 17 maio 2017.

BRASIL. Ministério da Agricultura, Pecuária e Abastecimento. Portaria no 795, de 15 de dezembro de $1993 . \quad$ Brasília, 2009. Disponível em: <http://sistemasweb.agricultura.gov.br/sislegis/action/detalhaAto.do?method=visualizarAtoPortal Mapa\&chave=1431040401>. Acesso em: 28 fev. 2017.

CARVALHO, M.; PALADINI, E. Gestão da Qualidade: Teorias e Casos. 2 ed. Rio de Janeiro: Eliever, 2012.

LOBO, R. Gestão da Qualidade. São Paulo: Editora Érica Ltda, 2010.

MELLO, C.H..P. Controle da qualidade on-line. Gestão da qualidade. São Paulo: Pearson, 2011. Disponível em:<http://unoeste.bv3.digitalpages.com.br/users/publications/9788576056997/pages/87>. Acesso em: 06 maio 2017.

RODRIGUES, A. Pesquisa mercadológica. São Paulo: Pearson Education do Brasil, 2015. Disponível em: <http://unoeste.bv3.digitalpages.com.br/users/publications/9788543012131/pages/-12>. Acesso em: 07 maio 2017.

SELEME, R. STADLER, H. Controle da Qualidade: As Ferramentas Necessárias. 2 ed. Curitiba: Ibpex, 2010 